\title{
An overview of patients with urothelial bladder cancer over the past two decades: a Surveillance, Epidemiology, and End Results (SEER) study
}

\author{
Yan Zang ${ }^{1 \#}$, Xiao $\mathrm{Li}^{2 \#}$, Yifei Cheng ${ }^{3 \#}$, Feng $\mathrm{Qi}^{2}$, Ningli Yang ${ }^{1}$ \\ ${ }^{1}$ Department of Bariatric and Metabolic Surgery, The First Affiliated Hospital of Nanjing Medical University, Nanjing, China; ${ }^{2}$ Department of \\ Urologic Surgery, Jiangsu Cancer Hospital \& Jiangsu Institute of Cancer Research \& Affiliated Cancer Hospital of Nanjing Medical University, \\ Nanjing, China; ${ }^{3}$ Department of Urology, The First Affiliated Hospital of Nanjing Medical University, Nanjing, China \\ Contributions: (I) Conception and design: F Qi, N Yang; (II) Administrative support: None; (III) Provision of study materials or patients: Y Zang, X \\ Li, Y Cheng; (IV) Collection and assembly of data: F Qi, Y Zang, X Li; (V) Data analysis and interpretation: F Qi, Y Cheng; (VI) Manuscript writing: \\ All authors; (VII) Final approval of manuscript: All authors. \\ \#These authors contributed equally to this work. \\ Correspondence to: Feng Qi. Department of Urologic Surgery, Jiangsu Cancer Hospital \& Jiangsu Institute of Cancer Research \& Affiliated Cancer \\ Hospital of Nanjing Medical University, Nanjing 210009, China. Email: qf199408@163.com; Ningli Yang. Department of Bariatric and Metabolic \\ Surgery, The First Affiliated Hospital of Nanjing Medical University, Nanjing 210029, China. Email: njyangningli2002@163.com.
}

Background: To explore the overall trends of incidence rate (IR), mortality and survival outcomes of patients with urothelial bladder cancer (UBC) over the past two decades.

Methods: Patients diagnosed with UBC from 1993 to 2012 were extracted from the Surveillance, Epidemiology and End Result (SEER) 18 database. Baseline characteristics and treatment types of included patients were collected retrospectively. Moreover, the age-adjusted IRs and annual percent changes (APCs) were obtained. Afterwards, we calculated the standardized mortality ratios (SMRs) for bladder cancer (BC), cardiovascular disease (CVD) and all-cause mortality by comparing UBC cases with the general population. Finally, survival outcomes of UBC patients were analyzed and compared.

Results: A total of 220,405 UBC patients were identified, including 167,036 (75.79\%) male patients and $53,369(24.21 \%)$ female patients, with an average age of 70.84 years old. Most patients were White $(89.85 \%)$, with older age $(71.67 \%,>65$ years old), lower $\mathrm{T}$ stage diseases $(78.11 \%,<\mathrm{T} 2)$ and lower median household income (55.37\%). When compared with patients diagnosed between 1993 and 2002, those diagnosed between 2003 and 2012 had older age (mean: 71.15 vs. 70.16 years old, $\mathrm{P}<0.001$ ), higher proportion of men (76.22\% vs. $74.83 \%, \mathrm{P}<0.001)$ and lower median household income (56.69\% vs. $52.50 \%, \mathrm{P}<0.01)$. Overall, the IR of UBC increased slightly before 2003 and maintained a stable trend of about 20 per 100,000 personyears after 2003. Additionally, CVD was recognized as an important cause of death (COD) of UBC patients. UBC patients were 44.5 times more likely to die of CVD when compared with the general population. Furthermore, the 3-, 5- and 10-year overall survival (OS) and cancer-specific survival (CSS) rates were $0.709,0.609$ and 0.421 , and $0.861,0.831$ and 0.789 , respectively. Finally, survival outcomes between patients diagnosed in the two periods (1993-2002 vs. 2003-2012) were not significantly different.

Conclusions: The IR of UBC increased slightly before 2003 and remained stable after 2003. UBC patients had higher CVD burden than the general population. Hence, cardiovascular health should be emphasized to reduce mortality after UBC diagnosis. Lastly, survival outcomes of UBC patients in the last two decades showed no significant difference.

Keywords: Incidence; mortality; survival; the Surveillance, Epidemiology and End Result (SEER); urothelial bladder cancer (UBC) 
Submitted Mar 02, 2020. Accepted for publication Sep 25, 2020.

doi: $10.21037 /$ atm-20-2108

View this article at: http://dx.doi.org/10.21037/atm-20-2108

\section{Introduction}

Bladder cancer (BC) is one of the most common malignancies worldwide (1). The estimated global new cases and deaths of BC in 2018 were 549,393 and 199,922, respectively (2). Based on the depth of tumor infiltration, $\mathrm{BC}$ is divided into non-muscle invasive $\mathrm{BC}$ (NMIBC) and muscle invasive $\mathrm{BC}$ (MIBC). About three-fourths of new BC cases are NMIBC at their initial diagnosis (3). Generally, patients with NMIBC have better prognosis than those with MIBC. Previous studies reported that the 5- and 10-year overall survival (OS) rates of MIBC patients were about $50 \%$ and $36 \%$, respectively, even with aggressive management $(4,5)$. Moreover, the 5 -year OS rate of metastatic diseases was only $15 \%$.

Although the majority of $\mathrm{BC}$ patients are non-invasive at initial diagnosis, the possibilities of progression and recurrence in NMIBC patients are very high. Studies $(6,7)$ reported that $10-20 \%$ of NMIBC patients progressed to MIBC and approximately $50-70 \%$ recurred over time. Therefore, continuous monitoring and surveillance (including regular cystoscopy and intravesical therapy) are essential for NMIBC cases treated with transurethral resection of bladder tumor (TURBt) (8). As a result, $\mathrm{BC}$ brings heavy economic and psychological burden to patients.

The incidence rate (IR) of $\mathrm{BC}$ in the male population is about three times higher than that in women (9). Generally, $\mathrm{BCs}$ are infrequently detected in individuals younger than 40 years old, and the median age at diagnosis ranges from 65 to 74 years old in different studies $(5,9)$. In addition, Lee et al. (10) demonstrated that the IR, mortality and survival outcomes of BC were significantly different in patients with different races. The IR of BC in Whites was two times higher than that in African Americans, while the latter had higher tumor stages and worse prognosis.

Urothelial bladder cancer (UBC) is the most common subtype of BC, accounting for $95 \%$ of $\mathrm{BC}$ cases (11). In this study, we provided a comprehensive overview of UBC patients during the past 20 years (1993-2012) on the basis of the National Cancer Institute's (NCI) Surveillance, Epidemiology, and End Results (SEER) program. Furthermore, comparisons between patients diagnosed in the two periods (1993-2002 vs. 2003-2012) were made in basic characteristics, IR, mortality and survival outcomes. We present the following article in accordance with the STROBE reporting checklist (available at http://dx.doi. org/10.21037/atm-20-2108).

\section{Methods}

\section{Database}

All the original data were downloaded from the SEER database retrospectively. Outcomes of cancer incidence, mortality and long-term follow-up were included in this public and population-based database. SEER 9 was first constructed in 1971 and collected data from 9 registries in Connecticut, Hawaii, New Mexico, Utah, Iowa, San Francisco Oakland (California), Seattle-Puget Sound (Washington), Detroit (Michigan) and Atlanta (Georgia). In 1992, SEER 13 was developed with four additional areas added in [including Alaska Natives, San Jose-Monterey (California), Los Angeles and rural Georgia]. Moreover, SEER 18 was created with five more registries (Greater California, New Jersey, Louisiana, Greater Georgia and Kentucky) at the beginning of the 21st century. Nowadays, with increasing regions participating in this programme, SEER 18 registry accounts for approximately $30 \%$ of the total US population. This study was exempt from the Institutional Review Board (IRB) approval because the original data were from a public database. All procedures performed in studies were in accordance with the national research committee and with the Declaration of Helsinki (as revised in 2013).

\section{Patient identification}

Patients diagnosed with UBC with positive pathology from 1993 to 2012 were extracted from SEER 18 utilizing the SEER*Stat software. The inclusion criteria were as follows: (I) diagnosed as UBC (C67.0-67.9, International Classification of Diseases for Oncology: 8220-8139) with positive histological confirmation; (II) the latest year of diagnosis was 2012 to ensure a follow-up period of at least 5 years; (III) complete data were available with active 
Table 1 SEER stage crosswalk for defining T classification

\begin{tabular}{lcc}
\hline \multirow{2}{*}{ T classification } & \multicolumn{2}{c}{ Diagnosis years } \\
\cline { 2 - 3 } & \multicolumn{1}{c}{ 1993-2003, EOD extension, 3rd ed } & 2004-2012, CS extension \\
\hline Ta & $01,03,05$ & 010,030 \\
Tis & $00,06,10$ & 060,100 \\
T1 & 15,30 & $150,155,160,165,170,300$ \\
$\geq$ T2 & $20-23,40-85$ & $200-240,400-810$
\end{tabular}

SEER, Surveillance, Epidemiology, and End Results; CS, collaborative staging; EOD, extent of disease.

follow-up. Furthermore, patients with the type of reporting source being autopsy only or a death certificate were excluded.

\section{Baseline characteristics}

We extracted baseline characteristics and treatment types of each patient using the "Case Listing Session" tool of the SEER*Stat software. Variables included age at diagnosis, year of diagnosis, race, sex, marital status, census regions, county level median household income, primary tumor site, tumor grade, histology, TNM stage, extent of disease (EOD), the administration of surgery, radiotherapy and chemotherapy, vital status, cause of death (COD) and survival time.

In this study, age at diagnosis was divided into six groups, including $<35,35-44,45-54,55-64,65-74$ and $\geq 75$ years old. Race was classified into White, Black and Other. Historic stage was categorized into localized, regional and distant. Low and high levels of household income were defined based on the median value. When defining $T$ classification, EOD Extension $3^{\text {rd }}$ edition was applied for patients diagnosed prior to 2003, and collaborative staging (CS) extension was used for patients diagnosed after 2003. A crosswalk for $\mathrm{T}$ stage definition is presented in Table 1. Additionally, CODs were divided into "died of UBC" and "died of other cause". We separated cardiovascular disease (CVD) from other causes for deeper discussion due to the relationship between CVD and UBC.

\section{IR trend and annual percent change (APC)}

The age-adjusted IRs were obtained utilizing the "Rate Session" tool of the SEER*Stat software. SEER 13 was used to extract the IRs for patients from 1993 to 1999, and SEER 18 was for patients from 2000 to 2012. To make comparisons between patients diagnosed in the last two decades, we discussed the IRs in the whole population, and further stratified by gender, race and age. Additionally, the APCs were calculated to identify the IRs trends for different populations.

\section{Proportional mortality ratio (PMR)}

PMR was defined as the number of deaths due to a specific cause divided by the number of total deaths. In this study, CODs consisted of BC, CVD and other causes. Furthermore, subgroup analyses by clinical variables were conducted, including gender, age at diagnosis, race, $\mathrm{T}$ stage, time since diagnosis, median household income, histologic stage and the history of a prior malignancy.

\section{Standardized mortality ratio (SMR)}

In this study, we compared the all-cause/CVD mortality of UBC patients with the US population, and defined it as the SMR. SMR was calculated as the observed deaths divided by the expected deaths. It was convenient to obtain the age-specific risks of all-cause/CVD mortality from the Centers for Disease Control and Prevention Wide-ranging Online Data for Epidemiologic Research (WONDER) Tool (https://wonder.cdc.gov/). The expected deaths for different age groups were calculated by multiplying the number of UBC patients in each age category by age-specific crude risk in the general population. Lastly, 95\% confidence intervals (CIs) for the SMRs were calculated according to the BoiceMonson method.

\section{Survival outcomes}

Kaplan-Meier (KM) analyses were performed to explore the survival outcomes of UBC patients in different periods. 
A total 1,477 patients were excluded when calculating the cancer-specific survival (CSS) because of unknown COD. In addition, the 3- and 5-year OS and CSS rates were calculated for further comparisons.

\section{Statistical analysis}

The age-adjusted IRs and basic characteristics were obtained based on the 2000 US Standard population using the SEER*Stat software (version 8.3.6; www.seer.cancer. gov/seerstat). Comparisons between UBC patients in the past two decades were performed by Chi-square tests for categorical variables and $t$-tests for continuous variables. The APCs were calculated and generated by Joinpoint Regression Program (https://surveillance.cancer.gov/ joinpoint/). The entire analyses were performed via SPSS 23.0 software (SPSS Inc., Chicago, IL, USA) and R software (version 3.4.1). Two-sided $\mathrm{P}<0.05$ was considered to be statistically significant.

\section{Results}

\section{Basic characteristics}

A total of 220,405 UBC patients were identified, including 167,036 males and 53,369 females, with an average age of 70.84 years old (Table 2). Generally, most patients were White $(89.85 \%)$, with older age $(71.67 \%,>65$ years old), lower $\mathrm{T}$ stage diseases $(78.11 \%,<\mathrm{T} 2)$ and lower median household income (55.37\%). When compared with patients diagnosed between 1993 and 2002, those diagnosed between 2003 and 2012 had older age (mean: 71.15 vs. 70.16 years old, $\mathrm{P}<0.001)$, higher proportion of men (76.22\% vs. $74.83 \%, \mathrm{P}<0.001)$ and lower median household income $(56.69 \%$ vs. $52.50 \%, \mathrm{P}<0.01)$. Furthermore, patients diagnosed between 2003 and 2012 had higher proportion of N0 diseases $(93.68 \%$ vs. $81.26 \%, \mathrm{P}<0.001)$. When it came to tumor site, there was no obvious difference in the overall trends between patients diagnosed in the two periods. However, significant difference still existed in the internal

Table 2 Description of population-based cohort of patients with urothelial bladder cancer

\begin{tabular}{|c|c|c|c|c|}
\hline Variables & Total & 1993-2002 & 2003-2012 & $P$ value \\
\hline Age, year, mean $\pm S D$ & $70.84 \pm 12.08$ & $70.16 \pm 12.16$ & $71.15 \pm 12.03$ & $<0.001$ \\
\hline$<35$ & $1,204(0.55)$ & $483(0.70)$ & $721(0.48)$ & $<0.001$ \\
\hline $35-44$ & $4,099(1.86)$ & $1,653(2.38)$ & $2,446(1.62)$ & \\
\hline $55-64$ & $40,606(18.42)$ & $12,214(17.62)$ & 28,392 (18.79) & \\
\hline $65-74$ & $64,413(29.22)$ & $21,490(31.00)$ & $42,923(28.41)$ & \\
\hline$\geq 75$ & $93,557(42.45)$ & $27,825(40.14)$ & $65,732(43.50)$ & \\
\hline Race, n (\%) & & & & $<0.001$ \\
\hline Other & $9,056(4.11)$ & $2,965(4.28)$ & $6,091(4.03)$ & \\
\hline Unknown & $1,439(0.65)$ & $235(0.34)$ & $1,204(0.80)$ & \\
\hline Sex, n (\%) & & & & $<0.001$ \\
\hline Male & $167,036(75.79)$ & $51,868(74.83)$ & $115,168(76.22)$ & \\
\hline Female & $53,369(24.21)$ & $17,446(25.17)$ & $35,923(23.78)$ & \\
\hline
\end{tabular}

Table 2 (continued) 
Table 2 (continued)

\begin{tabular}{|c|c|c|c|c|}
\hline Variables & Total & 1993-2002 & 2003-2012 & P value ${ }^{1}$ \\
\hline Grade I & $31,428(14.26)$ & $11,867(17.12)$ & $19,561(12.95)$ & \\
\hline Grade II & $64,916(29.45)$ & $25,870(37.32)$ & $39,046(25.84)$ & \\
\hline Grade III & $49,409(22.42)$ & $19,576(28.24)$ & $29,833(19.75)$ & \\
\hline Unknown & $27,998(12.70)$ & $4,441(6.41)$ & 23,557 (15.59) & \\
\hline Histology, n (\%) & & & & $<0.001$ \\
\hline Localized & $171,208(77.68)$ & $53,523(77.22)$ & $117,685(77.89)$ & \\
\hline Regional & 39,607 (17.97) & $12,491(18.02)$ & $27,116(17.95)$ & \\
\hline T stage, n (\%) & & & & $<0.001$ \\
\hline$<\mathrm{T} 2$ & $172,161(78.11)$ & $53,611(77.35)$ & $118,550(78.46)$ & \\
\hline$\geq \mathrm{T} 2$ & $44,841(20.34)$ & $14,295(20.62)$ & $30,546(20.22)$ & \\
\hline Tx & $3,403(1.54)$ & $1,408(2.03)$ & 1,995 (1.32) & \\
\hline Median household income ${ }^{2}, \mathrm{n}(\%)$ & & & & $<0.001$ \\
\hline Low & $122,036(55.37)$ & $36,389(52.50)$ & 85,647 (56.69) & \\
\hline High & $98,341(44.62)$ & $32,915(47.49)$ & $65,426(43.30)$ & \\
\hline Unknown & $28(0.01)$ & $10(0.01)$ & $18(0.01)$ & \\
\hline With previous primary, n (\%) & & & & $<0.001$ \\
\hline No & $166,112(75.37)$ & $54,558(78.71)$ & $111,554(73.83)$ & \\
\hline Yes & $54,293(24.63)$ & $14,756(21.29)$ & $39,537(26.17)$ & \\
\hline Cancer-directed surgery, n (\%) & & & & $<0.001$ \\
\hline $\mathrm{No}^{3}$ & $12,067(5.47)$ & $3,502(5.05)$ & $8,565(5.67)$ & \\
\hline Yes & $207,845(94.30)$ & $65,711(94.80)$ & $142,134(94.07)$ & \\
\hline Unknown & $493(0.22)$ & $101(0.15)$ & $392(0.26)$ & \\
\hline
\end{tabular}

1, comparison between 1993-2002 and 2003-2012; ${ }^{2}$, median household income: defined by earnings above the median of the median household income in this sample; ${ }^{3}$, including "no surgical procedure", "needle, or aspiration biopsy" or "Non-cancer directed surgery". Grade I = well differentiated; Grade II = moderately differentiated; Grade III = poorly differentiated; Grade IV = undifferentiated; anaplastic. UBC, urothelial bladder cancer; SD, standard deviation. 
distribution $(\mathrm{P}<0.001$, Table $\mathrm{S} 1)$.

\section{IR trend and APC}

Overall, the IR of UBC increased slightly before 2003 and maintained a stable trend of about 20 per 100,000 personyears after 2003. Among the male population, this trend was consistent with that in the whole population. The overall IR had been stable in the past 20 years in the female population,

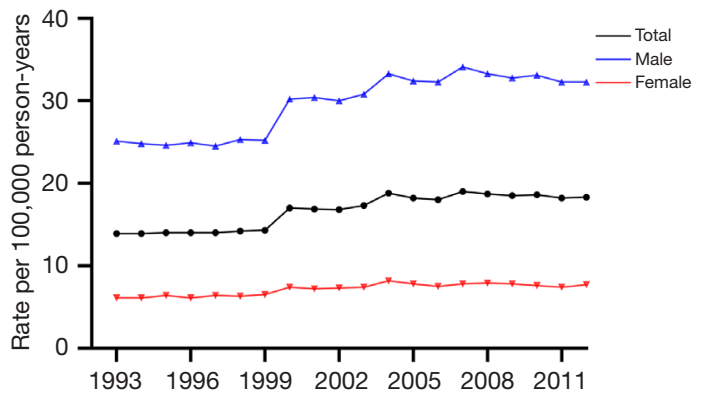

Figure 1 Incidence rates of urothelial bladder cancer in the general population, male and female from 1993 to 2012. maintaining around 8.0 per 100,000 person-years (Figure 1).

Overall, the IR increased with the increasing of age. However, for patients under 75 years old, the IR of UBC had been stable in all age groups in the last two decades. For patients over 75 years old, the IR increased slightly before 2003, and maintained stable after 2003 (140/100,000, Figure 2). As for race categorization, the IRs of Blacks and others remained at about 11.0 and 8.0 per 100,000 personyears respectively. The IR of Whites increased slightly before 2003 and remained at about 20.0 per 100,000 person-years after 2003. For further race-age classification, the IRs of Blacks and others were relatively stable at all age groups. For Whites, the IR trends in all age groups were similar to those in the whole population (Figure 3).

Moreover, subsequent analyses by sex showed the similar IR trends with the whole population. However, in female Blacks and others, the IR in people aged over 65 years old fluctuated greatly, which was mainly because of the small number of cases in this population (Figure 4).

As shown in Figure 5, the Joinpoint regression figures indicate that the APCs before 2004 in different populations were statistically significant. The APC before 2004 was 2.95 ,
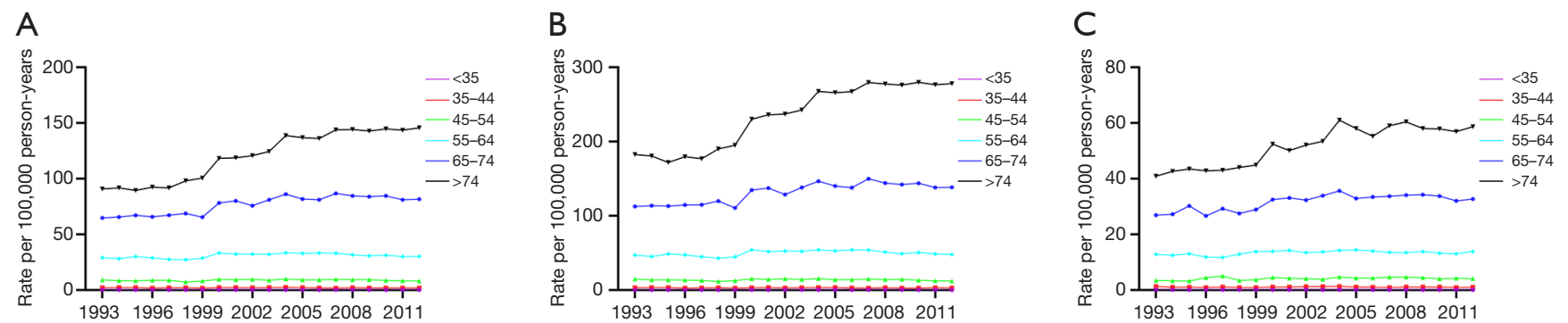

Figure 2 Incidence rates of urothelial bladder cancer in the general population (A), male (B) and female (C) stratified by age from 1993 to 2012.

A

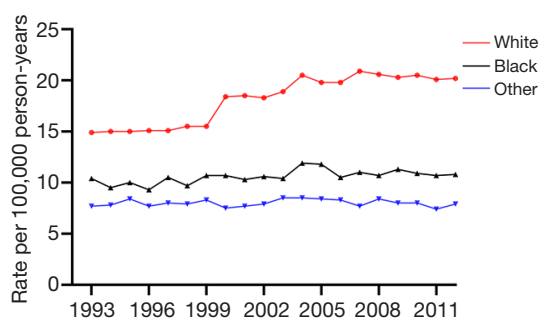

B

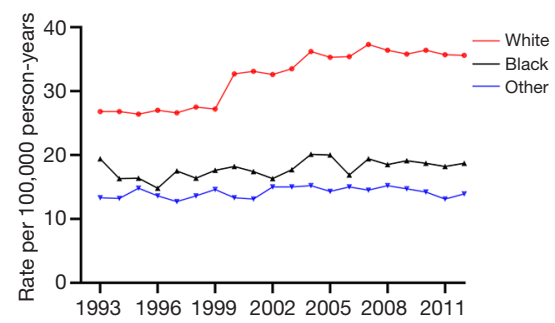

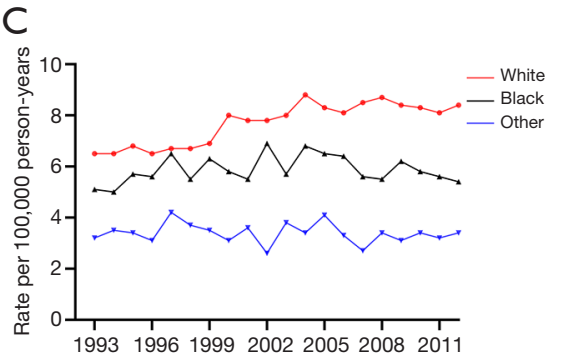

Figure 3 Incidence rates of urothelial bladder cancer in the general population (A), male (B) and female (C) stratified by race from 1993 to 2012. 

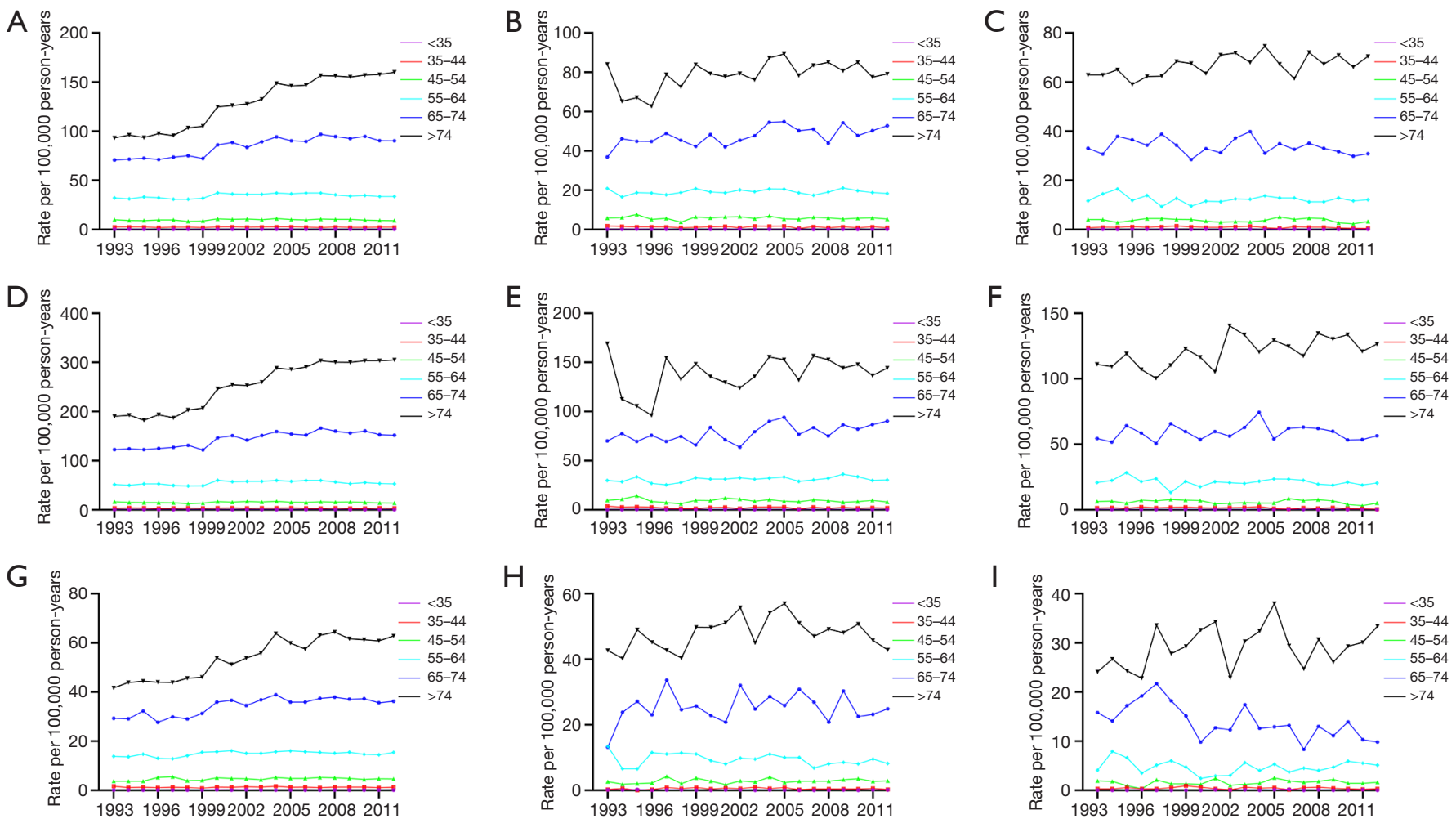

Figure 4 Incidence rates of urothelial bladder cancer in the general population (A,B,C), male (D,E,F) and female (G,H,I) stratified by raceage (A, D and G for White; B, E and H for Black; C, F and I for Other) from 1993 to 2012.
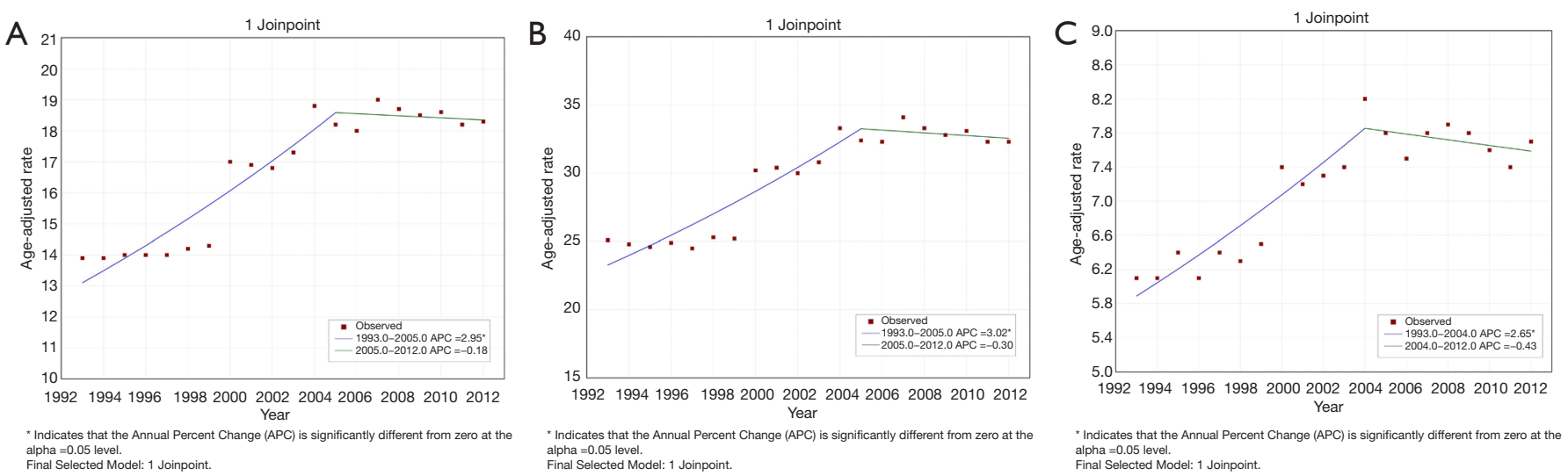

Figure 5 Annual percentage change curves for different populations: the general population (A), male (B) and female (C).

3.02 and 2.65 for the whole, male and female populations, respectively (all $\mathrm{P}<0.05)$.

\section{Proportional mortality ratio}

A total of 131,585 UBC patients died up to the last follow- up (December 31, 2017). Among them, 39,030 patients died of $\mathrm{BC}, 30,881$ patients died of CVD, and the remaining patients died of other causes (data not tabled). The PMRs of each COD are shown in Figure 6A, and further stratified by age at diagnosis (Figure 6B), gender (Figure 6C), race (Figure 6D), median household income (Figure 6E), the 

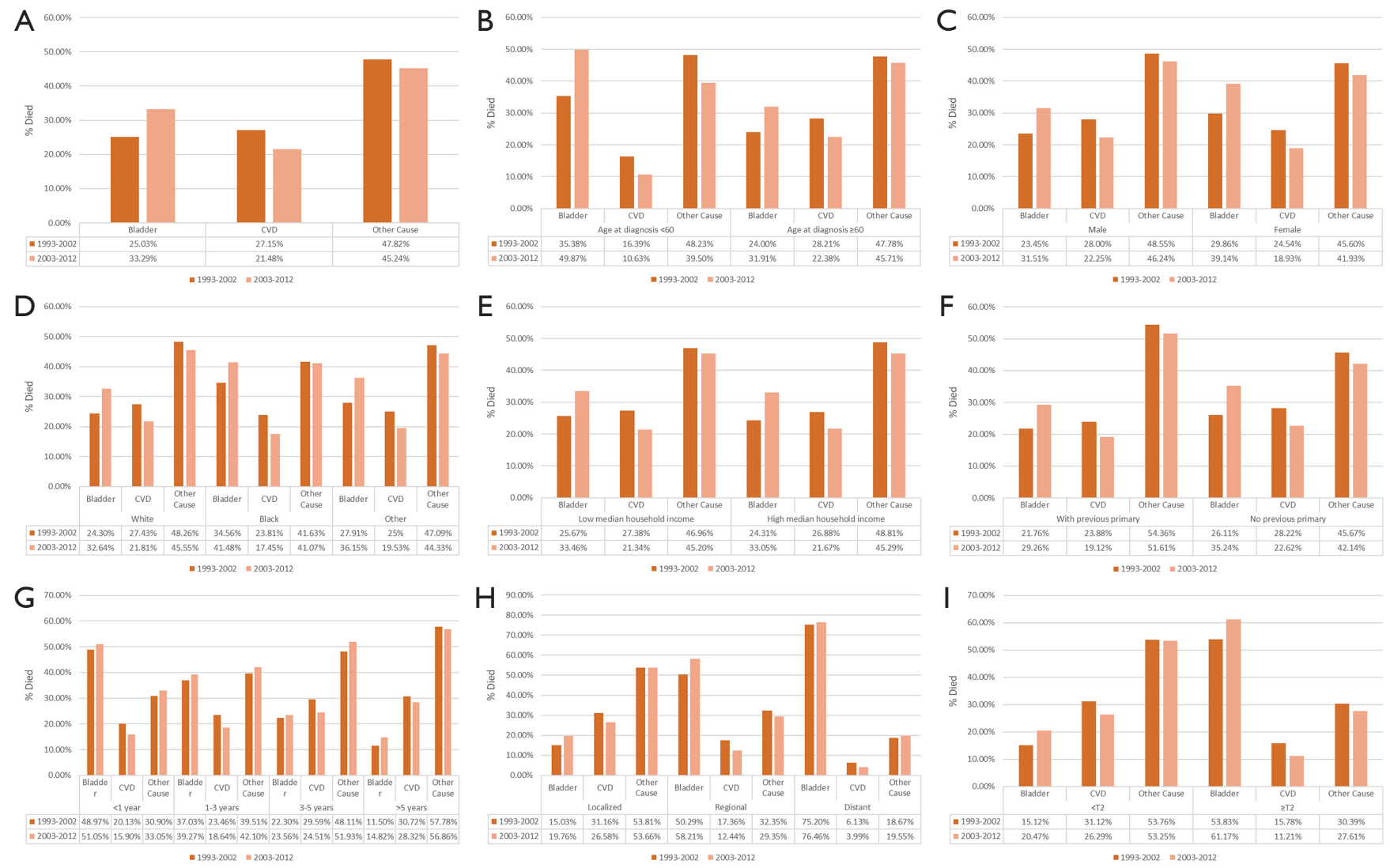

Figure 6 Proportional mortality ratios for general population (A), and further stratified by age at diagnosis (B), gender (C), race (D), median household income $(\mathrm{E})$, previous primary malignancy $(\mathrm{F})$, time since diagnosis $(\mathrm{G})$, historic stage $(\mathrm{H})$, and $\mathrm{T}$ stage $(\mathrm{I})$.

history of a prior malignancy (Figure $6 F$ ), time to diagnosis (Figure 6G), histological type (Figure $6 H$ ) and $\mathrm{T}$ stage (Figure 6I).

In patients diagnosed between 2003 and 2012, the proportion of BC-specific deaths increased and CVDspecific deaths decreased when compared with patients diagnosed between 1993 and 2002. As shown in Figure $6 B$, the largest increase in BC-specific deaths was detected in patients younger than 60 years old. When compared with patients over 60 years old, the proportion of BC-specific deaths was higher and the proportion of CVD-specific deaths was lower in patients younger than 60 years old. Furthermore, as the time to diagnosis increased, the proportion of $\mathrm{BC}$-specific deaths was decreasing, while the proportions of CVD/other causesspecific deaths was increasing. Conversely, as the histological level progressed (localized vs. regional vs. distant), the proportion of $\mathrm{BC}$-specific deaths increased significantly, while the proportion of $\mathrm{CVD} /$ other causes- specific deaths decreased significantly. Furthermore, Blacks were more likely to die of BC than other races. However, no significant difference was found in the subgroup analyses by gender, the history of a prior malignancy and the median household income.

\section{$S M R$}

The SMR analysis was limited to patients diagnosed between 1999 and 2012 due to that fact that data on WONDER online databases were recorded only from 1999 to 2017. Comparisons between the general population and UBC cases in the age-specific risks of BC, CVD and allcause mortality are presented in Table 3. UBC patients had higher BC, CVD and all-cause mortality than the general population. Similarly, higher mortality could be seen in both male and female populations. Overall, UBC patients were 3,905.6 times (95\% CI: 3,864.3-3,947.4) more likely to die of BC, 44.5 times (95\% CI: 43.9-45.0) more likely 
Table 3 Standardized mortality ratios of cardiovascular disease, bladder cancer and all-cause mortality, by age and gender, 1999-2012

\begin{tabular}{|c|c|c|c|c|c|}
\hline Age & Observed deaths & Number of UBC cases & Crude risk $^{1}$ & Expected deaths & SMR (95\% Cl) \\
\hline$<35$ years & 5 & 989 & 4.5 & 0.0 & $112.3(48.0-263.0)$ \\
\hline $35-44$ years & 34 & 3,368 & 35.5 & 1.2 & $28.4(20.4-39.7)$ \\
\hline $45-54$ years & 350 & 14,347 & 107.6 & 15.4 & $22.7(20.4-25.2)$ \\
\hline $65-74$ years & 5,573 & 55,342 & 652.8 & 361.3 & $15.4(15.0-15.8)$ \\
\hline$\geq 75$ years & 16,847 & 83,242 & $3,219.0$ & $2,679.6$ & $6.3(6.2-6.4)$ \\
\hline Male & 19,491 & 146,748 & 278.3 & 408.4 & $47.7(47.1-48.4)$ \\
\hline Female & 5,117 & 46,383 & 294.3 & 136.5 & $37.5(36.5-38.5)$ \\
\hline$<35$ years & 62 & 989 & 78.6 & 0.8 & 79.8 (62.2-102.2) \\
\hline $35-44$ years & 551 & 3,368 & 189.7 & 6.4 & $86.2(79.3-93.7)$ \\
\hline $45-54$ years & 3,409 & 14,347 & 421.2 & 60.4 & $56.4(54.6-58.3)$ \\
\hline $55-64$ years & 12,085 & 35,823 & 898.0 & 321.7 & 37.6 (36.9-38.2) \\
\hline $65-74$ years & 28,171 & 55,342 & $2,081.4$ & $1,151.9$ & $24.5(24.2-24.7)$ \\
\hline$\geq 75$ years & 64,081 & 83,242 & $7,759.0$ & $6,458.7$ & $9.9(9.8-10.0)$ \\
\hline Male & 82,784 & 146,748 & 829.5 & $1,217.3$ & $68.0(67.5-68.5)$ \\
\hline Female & 25,575 & 46,383 & 818.1 & 379.5 & $67.4(66.6-68.2)$ \\
\hline \multicolumn{6}{|c|}{ Bladder cancer mortality, $n=33,943$} \\
\hline $55-64$ years & 4,773 & 35,823 & 4.8 & 1.7 & $2,775.8(2,698.2-2,855.7)$ \\
\hline $65-74$ years & 8,482 & 55,342 & 14.7 & 8.1 & $1,042.6(1,020.7-1,065.0)$ \\
\hline$\geq 75$ years & 18,670 & 83,242 & 47.0 & 39.1 & $477.2(470.4-484.1)$ \\
\hline Male & 24,475 & 146,748 & 6.4 & 9.4 & 2,606.0 (2,573.5-2,638.8) \\
\hline Female & 9,468 & 46,383 & 2.7 & 1.3 & $7,560.2(7,409.5-7,714.1)$ \\
\hline Overall & 33,943 & 193,131 & 4.5 & 8.7 & $3,905.6(3,864.3-3,947.4)$ \\
\hline
\end{tabular}

${ }^{1}$, crude risk was calculated based on the US population (per 100,000); ${ }^{2}$, CVD mortality includes: diseases of heart (ICD 10 = 100-109, $111,113,120-151)$, hypertension without heart disease (ICD $10=110,112)$, cerebrovascular diseases (ICD $10=160-169)$, atherosclerosis $($ ICD $10=170)$, aortic aneurysm $($ ICD $10=171)$, other diseases of arteries, arterioles and capillaries (ICD 10 = 172-178). SMR, standardized mortality ratio; CVD, cardiovascular disease; UBC, urothelial bladder cancer; CI, confidence interval; ICD, International Classification of Diseases. 
Table 4 Survival probabilities of 3-, 5- and 10-year overall survival of urothelial bladder cancer patients, further stratified by age, gender and T stage

\begin{tabular}{|c|c|c|c|}
\hline Variables & 1993-2012 & 1993-2002 & 2003-2012 \\
\hline$<60$ years & $0.870(0.867-0.874)$ & $0.881(0.876-0.887)$ & $0.865(0.861-0.869)$ \\
\hline$\geq 60$ years & $0.674(0.672-0.676)$ & $0.671(0.667-0.675)$ & $0.676(0.673-0.678)$ \\
\hline Male & $0.715(0.712-0.717)$ & $0.720(0.716-0.723)$ & $0.712(0.710-0.715)$ \\
\hline$<\mathrm{T} 2$ & $0.802(0.800-0.804)$ & $0.805(0.802-0.808)$ & $0.800(0.798-0.802)$ \\
\hline$\geq \mathrm{T} 2$ & $0.365(0.360-0.369)$ & $0.366(0.359-0.374)$ & $0.364(90.359-0.369)$ \\
\hline 5-year OS & $0.609(0.607-0.611)$ & $0.609(0.605-0.613)$ & $0.608(0.606-0.611)$ \\
\hline$<60$ years & $0.830(0.827-0.834)$ & $0.841(0.834-0.847)$ & $0.825(0.820-0.830)$ \\
\hline Female & $0.605(0.601-0.609)$ & $0.596(0.589-0.604)$ & $0.609(0.604-0.614)$ \\
\hline$<\mathrm{T} 2$ & $0.696(0.694-0.698)$ & $0.698(0.694-0.702)$ & $0.695(0.693-0.698)$ \\
\hline$\geq \mathrm{T} 2$ & $0.284(0.280-0.288)$ & $0.285(0.278-0.293)$ & $0.284(0.279-0.289)$ \\
\hline 10-year OS & $0.421(0.419-0.423)$ & $0.421(0.417-0.425)$ & $0.421(0.418-0.424)$ \\
\hline$<60$ years & $0.747(0.743-0.752)$ & $0.755(0.748-0.763)$ & $0.745(0.739-0.751)$ \\
\hline$\geq 60$ years & $0.3520(0.348-0.353)$ & $0.344(0.341-0.349)$ & $0.354(0.350-0.357)$ \\
\hline Male & $0.417(0.415-0.420)$ & $0.420(0.415-0.424)$ & $0.417(0.413-0.420)$ \\
\hline Female & $0.433(0.428-0.437)$ & $0.426(0.418-0.433)$ & $0.436(0.430-0.433)$ \\
\hline
\end{tabular}

Data were HR $(95 \% \mathrm{Cl})$. Note: 3,403 patients were excluded due to the unknown T stage when stratified by T stage. OS, overall survival; UBC, urothelial bladder cancer; HR, hazard ratio; Cl, confidence interval.

to die of CVD and 68.1 times (95\% CI: 67.7-68.5) more likely to die of all causes when compared with the general population.

\section{Survival outcome}

We calculated the 3-, 5- and 10-year OS and CSS of the whole population, and further stratified by gender, T stage, age at diagnosis. The 3-, 5- and 10-year rates for OS and CSS were $0.709,0.609$ and 0.421 , and $0.861,0.831$ and 0.789 , respectively (Tables 4,5). Figure $7 A$ reveals that there was no significant difference between patients diagnosed in the two periods in OS $(\mathrm{P}=0.7319)$. However, significant difference was detected in the comparison of CSS
(Figure $7 B, \mathrm{P}<0.001)$. Moreover, comparisons stratified by clinical characteristics are shown in Figures S1,S2. For patients diagnosed in the two periods (1993-2002 vs. 20032012), the probabilities were 0.710 and 0.708 for 3 -year OS, 0.609 and 0.608 for 5 -year OS, and 0.421 and 0.421 for 10 -year OS, respectively (Table 4). As for CSS, the probabilities were 0.865 and 0.858 for 3 -year CSS, 0.836 and 0.829 for 5 -year CSS, and 0.796 and 0.786 for 10 -year CSS (Table 5). Therefore, the actual differences between patients diagnosed in the two periods were not obvious.

\section{Discussion}

Generally, most UBC patients had older age, lower median 
Table 5 Survival probabilities of 3-, 5- and 10-year cancer-specific survival of urothelial bladder cancer patients, further stratified by age, gender and $T$ stage

\begin{tabular}{|c|c|c|c|}
\hline Variables & 1993-2012 & 1993-2002 & 2003-2012 \\
\hline 3-year CSS & $0.861(0.859-0.862)$ & $0.865(0.863-0.868)$ & $0.858(0.857-0.860)$ \\
\hline$<60$ years & $0.916(0.913-0.918)$ & $0.925(0.921-0.930)$ & $0.911(0.907-0.914)$ \\
\hline$\geq 60$ years & $0.848(0.846-0.850)$ & $0.851(0.847-0.854)$ & $0.847(0.845-0.849)$ \\
\hline Male & $0.872(0.870-0.873)$ & $0.880(0.877-0.883)$ & $0.868(0.866-0.870)$ \\
\hline Female & $0.826(0.823-0.829)$ & $0.823(0.817-0.829)$ & $0.828(0.823-0.832)$ \\
\hline$\geq \mathrm{T} 2$ & $0.515(0.510-0.520)$ & $0.520(0.511-0.529)$ & $0.513(0.507-0.519)$ \\
\hline 5-year CSS & $0.831(0.830-0.833)$ & $0.836(0.833-0.839)$ & $0.829(0.827-0.831)$ \\
\hline$<60$ years & $0.899(0.896-0.902)$ & $0.907(0.902-0.912)$ & $0.895(0.891-0.898)$ \\
\hline$\geq 60$ years & $0.815(0.813-0.817)$ & $0.818(0.815-0.822)$ & $0.814(0.812-0.816)$ \\
\hline$<\mathrm{T} 2$ & $0.921(0.920-0.923)$ & $0.928(0.925-0.930)$ & $0.918(0.917-0.920)$ \\
\hline$\geq \mathrm{T} 2$ & $0.460(0.454-0.465)$ & $0.464(0.455-0.474)$ & $0.457(0.451-0.464)$ \\
\hline 10-year CSS & $0.789(0.787-0.791)$ & $0.796(0.793-0.799)$ & $0.786(0.784-0.789)$ \\
\hline$<60$ years & $0.876(0.872-0.879)$ & $0.884(0.878-0.889)$ & $0.872(0.868-0.877)$ \\
\hline$\geq 60$ years & $0.767(0.764-0.769)$ & $0.771(0.767-0.775)$ & $0.764(0.761-0.767)$ \\
\hline Male & $0.798(0.795-0.800)$ & $0.807(0.803-0.811)$ & $0.793(0.790-0.796)$ \\
\hline Female & $0.764(0.760-0.768)$ & $0.763(0.756-0.770)$ & $0.763(0.758-0.769)$ \\
\hline$<\mathrm{T} 2$ & $0.881(0.879-0.882)$ & $0.888(0.885-0.891)$ & $0.877(0.874-0.879)$ \\
\hline
\end{tabular}

Data were HR $(95 \% \mathrm{Cl})$. Note: 1,477 cases were excluded due to the unknown cause of death; 3,379 patients were excluded due to the unknown T stage when stratified by T stage. CSS, cancer-specific survival; UBC, urothelial bladder cancer; CI, confidence interval.
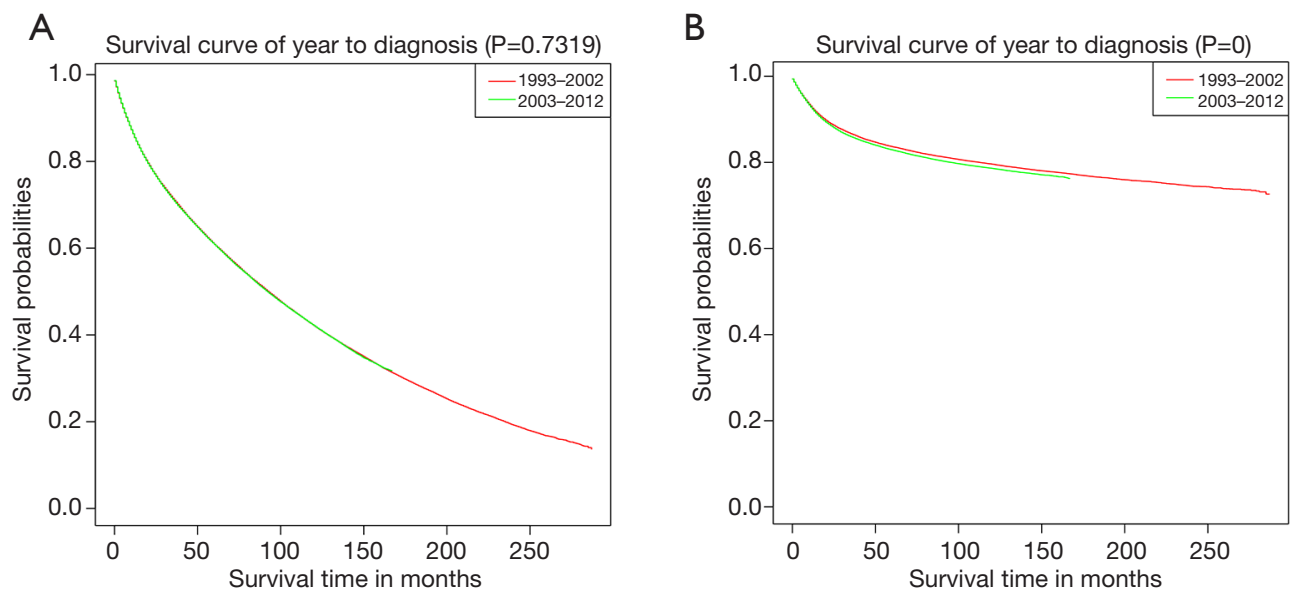

Figure 7 Kaplan-Meier curves of overall survival (A) and cancer-specific survival (B) for urothelial bladder cancer patients in different time periods. 
household income and lower T stage. When compared with patients diagnosed between 1993 and 2002, those diagnosed between 2003 and 2012 had older age, higher proportion of men and lower median household income. The IRs of UBC had a slight upward trend before 2003, and remained stable after 2003. In this study, CVD was considered to be an important COD. In patients diagnosed between 2003 and 2012, the proportion of BC-specific deaths increased when compared with that in patients diagnosed between 1993 and 2002. Additionally, the 3-, 5- and 10-year probabilities for OS were $0.709,0.609$ and 0.421 , and $0.861,0.831$ and 0.789 for CSS. Lastly, actual differences in survival outcomes between patients in the two periods were not obvious.

The median age at diagnosis of enrolled patients was 72.0 years old. The male-to-female ratio and the NMIBCto-MIBC ratio were both about 3:1. Basic characteristics of UBC patients in this study were broadly consistent with those of previous studies (5,12-14). Moreover, older age at diagnosis, higher proportion of non-invasive diseases and N0 stage diseases were found in patients diagnosed between 2003 and 2012. First of all, it suggested that the tumor burden caused by $\mathrm{BC}$ was decreasing due to the rapid development of medicine and economy. In addition, we found that the proportion of people who chose surgery reduced slightly over time. We attributed this to the fact that more and more treatment alternatives have been provided for UBC patients, including molecular targeted drugs $(15,16)$, neoadjuvant chemotherapy $(17,18)$, immunotherapy $(19,20)$ and so on.

Subsequently, we analyzed the main CODs of UBC patients. We found that CVD was one of the most important CODs. Many previous studies have investigated the relationship between cancer survivors and CVD. In a population-based cohort study (21) on the basis of the multiple linked UK electronic health records databases, conclusions could be drawn that the medium-term to longterm risk for CVD in survivors of most cancer types was higher than that in the general population. Felix et al. (22) demonstrated that female patients with endometrial cancer had higher CVD burden. Usually, women with endometrial cancer may experience excess CVD in any age category, especially in younger age groups. Furthermore, Bosco et al. (23) reported that androgen deprivation therapy for prostate cancer patients could increase the risk of CVD.

Many previous studies (24-28) have explored the critical role of smoking in the development and progression of BC. Hou et al. (29) found that former and current smoking status could increase the risk of recurrence and mortality in patients with BC. Masaoka and his teammates (30) declared that smoking was a persuasive risk factor for BC in Japanese. Other factors such as obesity (31-33), and diabetes (34-36) were also considered to be related to the occurrence and development of BC. Coincidentally, these factors are highly recognized to be tightly associated with the risk of CVD, which could well explain the higher proportion of CVD mortality in UBC patients.

In addition, we found that survival outcomes of UBC patients did not change significantly over the past 20 years. Nowadays, with the fast development of technology and medicine, increasing management manners for UBC have been emerged, including robot-assisted technology in surgery, the advent of molecular targeted drugs and immunotherapy. In theory, the mentioned above could extremely improve the prognosis of UBC patients. However, ideal survival improvement was not detected in this study. Jahnson et al. (37) performed a study based on the Swedish National Registry of Urinary Bladder Cancer (SNRUBC) to explore the changes in cancer characteristics, management and survival outcomes of BC patients over a period of 15 years (1997-2001 vs. 2002-2006 $v s .2007-2011)$. They found that the proportion of nonmuscle invasive diseases increased over time, and the management became more aggressive for all cancer stages. Despite these, survival outcomes exhibited no significant differences over time. It was probable that many patients in advanced stages with extravesical involvement would only benefit little in survival outcomes $(38,39)$. Additionally, cystectomy is a palliative treatment for many patients due to the older age, higher comorbidity or advanced stages (37). On the contrary, Engholm et al. (40) investigated the 5-year relative survival of patients with $\mathrm{BC}$ diagnosed in the Nordic countries between 1964 and 2003, and found that the relative survival of BC patients improved significantly over time.

Nevertheless, several limitations should not be ignored in our study. Firstly, the absence of related information regarding to the risk factors (such as socio-economic, lifestyle, and dietary changes) made it difficult to investigate a direct interpretation of the role over time. Secondly, it was a descriptive and retrospective study, leading to unavoidable sources of bias and variations. Additionally, data on tumor stages or size were limited, causing a potential bias during the analysis procedure. Although the SEER database has its own defects, it covers approximately $30 \%$ of the US population. However, it is one of the best databases to 
investigate the incidence, mortality and survival outcomes of cancer patients.

In conclusion, incidence of UBC increased slightly before 2003 and maintained a stable trend of about 20 per 100,000 person-years after 2003. Patients with UBC were with higher CVD burden than the general population. Moreover, comparisons between patients in the last two decades showed no obvious changes in survival outcomes. Further studies to identify suitable CVD screening strategies and interventions in this population are warranted.

\section{Acknowledgments}

Funding: This study was supported by the National Natural Science Foundation of China (No. 81702520), the Medical Research Project of Jiangsu Provincial Health and Family Planning Commission (No. H2018052), the Research Project of Jiangsu Cancer Hospital (No. ZN201602), and the young talents program of Jiangsu Cancer Hospital (No. 2017YQL-04).

\section{Footnote}

Reporting Checklist: The authors have completed the STROBE reporting checklist. Available at http://dx.doi. org/10.21037/atm-20-2108

Conflicts of Interest: All authors have completed the ICMJE uniform disclosure form (available at http://dx.doi. org/10.21037/atm-20-2108). XL serves as an unpaid Section Editor of Annals of Translational Medicine from Oct 2019 to Sep 2020. The other authors have no conflicts of interest to declare.

Ethical Statement: The authors are accountable for all aspects of the work in ensuring that questions related to the accuracy or integrity of any part of the work are appropriately investigated and resolved. All procedures performed in studies were in accordance with the national research committee and with the Declaration of Helsinki (as revised in 2013). This study was exempt from Institutional Review Board (IRB) approval because the original data were from a public database.

Open Access Statement: This is an Open Access article distributed in accordance with the Creative Commons Attribution-NonCommercial-NoDerivs 4.0 International License (CC BY-NC-ND 4.0), which permits the non- commercial replication and distribution of the article with the strict proviso that no changes or edits are made and the original work is properly cited (including links to both the formal publication through the relevant DOI and the license). See: https://creativecommons.org/licenses/by-nc-nd/4.0/.

\section{References}

1. Ferlay J, Steliarova-Foucher E, Lortet-Tieulent J, et al. Cancer incidence and mortality patterns in Europe: estimates for 40 countries in 2012. Eur J Cancer 2013;49:1374-403.

2. Bray F, Ferlay J, Soerjomataram I, et al. Global cancer statistics 2018: GLOBOCAN estimates of incidence and mortality worldwide for 36 cancers in 185 countries. CA Cancer J Clin 2018;68:394-424.

3. Sanchez A, Wszolek MF. Bladder cancer: Quality of life in patients with non-muscle-invasive bladder cancer. Nat Rev Urol 2015;12:186-8.

4. International Collaboration of Trialists; Medical Research Council Advanced Bladder Cancer Working Party (now the National Cancer Research Institute Bladder Cancer Clinical Studies Group); European Organisation for Research and Treatment of Cancer Genito-Urinary Tract Cancer Group, et al. International phase III trial assessing neoadjuvant cisplatin, methotrexate, and vinblastine chemotherapy for muscle-invasive bladder cancer: longterm results of the BA06 30894 trial. J Clin Oncol 2011;29:2171-7. doi:10.1200/JCO.2010.32.3139

5. Nielsen ME, Smith AB, Meyer AM, et al. Trends in stage-specific incidence rates for urothelial carcinoma of the bladder in the United States: 1988 to 2006 . Cancer 2014;120:86-95.

6. Kaufman DS, Shipley WU, Feldman AS. Bladder cancer. Lancet 2009;374:239-49.

7. Wallerand H, Bernhard JC, Culine S, et al. Targeted therapies in non-muscle-invasive bladder cancer according to the signaling pathways. Urol Oncol 2011;29:4-11.

8. Morgan TM, Clark PE. Bladder cancer. Curr Opin Oncol 2010;22:242-9.

9. Clark PE, Agarwal N, Biagioli MC, et al. Bladder cancer. J Natl Compr Canc Netw 2013;11:446-75.

10. Lee CT, Dunn RL, Williams C, et al. Racial disparity in bladder cancer: trends in tumor presentation at diagnosis. J Urol 2006;176:927-33; discussion 933-4.

11. Al-Husseini MJ, Kunbaz A, Saad AM, et al. Trends in the incidence and mortality of transitional cell carcinoma of the bladder for the last four decades in the USA: a SEER- 
based analysis. BMC Cancer 2019;19:46.

12. Mallin K, David KA, Carroll PR, et al. Transitional cell carcinoma of the bladder: racial and gender disparities in survival (1993 to 2002), stage and grade (1993 to 2007). J Urol 2011;185:1631-6.

13. Patafio FM, Robert Siemens D, Wei X, et al. Is there a gender effect in bladder cancer? A population-based study of practice and outcomes. Can Urol Assoc J 2015;9:269-74.

14. Brandt MP, Gust KM, Mani J, et al. Nationwide analysis on the impact of socioeconomic land use factors and incidence of urothelial carcinoma. Cancer Epidemiol 2018;52:63-9.

15. Felsenstein KM, Theodorescu D. Precision medicine for urothelial bladder cancer: update on tumour genomics and immunotherapy. Nat Rev Urol 2018;15:92-111.

16. Sjodahl G, Jackson CL, Bartlett JM, et al. Molecular profiling in muscle-invasive bladder cancer: more than the sum of its parts. J Pathol 2019;247:563-73.

17. Yin M, Joshi M, Meijer RP, et al. Neoadjuvant Chemotherapy for Muscle-Invasive Bladder Cancer: A Systematic Review and Two-Step Meta-Analysis. Oncologist 2016;21:708-15.

18. Vetterlein MW, Wankowicz SAM, Seisen T, et al. Neoadjuvant chemotherapy prior to radical cystectomy for muscle-invasive bladder cancer with variant histology. Cancer 2017;123:4346-55.

19. Boegemann M, Aydin AM, Bagrodia A, et al. Prospects and progress of immunotherapy for bladder cancer. Expert Opin Biol Ther 2017;17:1417-31.

20. Aggen DH, Drake CG. Biomarkers for immunotherapy in bladder cancer: a moving target. J Immunother Cancer 2017;5:94.

21. Strongman H, Gadd S, Matthews A, et al. Medium and long-term risks of specific cardiovascular diseases in survivors of 20 adult cancers: a population-based cohort study using multiple linked UK electronic health records databases. Lancet 2019;394:1041-54.

22. Felix AS, Bower JK, Pfeiffer RM, et al. High cardiovascular disease mortality after endometrial cancer diagnosis: Results from the Surveillance, Epidemiology, and End Results (SEER) Database. Int J Cancer 2017;140:555-64.

23. Bosco C, Bosnyak Z, Malmberg A, et al. Quantifying observational evidence for risk of fatal and nonfatal cardiovascular disease following androgen deprivation therapy for prostate cancer: a meta-analysis. Eur Urol 2015;68:386-96.

24. Teleka S, Haggstrom C, Nagel G, et al. Risk of bladder cancer by disease severity in relation to metabolic factors and smoking: A prospective pooled cohort study of 800,000 men and women. Int J Cancer 2018;143:3071-82.

25. Temraz S, Haibe Y, Charafeddine M, et al. The unveiling of a new risk factor associated with bladder cancer in Lebanon. BMC Urol 2019;19:16.

26. Choi JB, Lee EJ, Han KD, et al. Estimating the impact of body mass index on bladder cancer risk: Stratification by smoking status. Sci Rep 2018;8:947.

27. Liss MA, White M, Natarajan L, et al. Exercise Decreases and Smoking Increases Bladder Cancer Mortality. Clin Genitourin Cancer 2017;15:391-5.

28. Shiota M, Yokomizo A, Takeuchi A, et al. Smoking effect on secondary bladder cancer after external beam radiotherapy for prostate cancer. Jpn J Clin Oncol 2016;46:952-7.

29. Hou L, Hong X, Dai M, et al. Association of smoking status with prognosis in bladder cancer: A meta-analysis. Oncotarget 2017;8:1278-89.

30. Masaoka H, Matsuo K, Ito H, et al. Cigarette smoking and bladder cancer risk: an evaluation based on a systematic review of epidemiologic evidence in the Japanese population. Jpn J Clin Oncol 2016;46:273-83.

31. Gild P, Ehdaie B, Kluth LA. Effect of obesity on bladder cancer and renal cell carcinoma incidence and survival. Curr Opin Urol 2017;27:409-14.

32. Lin $Y$, Wang $Y, W u ~ Q$, et al. Association between obesity and bladder cancer recurrence: A meta-analysis. Clin Chim Acta 2018;480:41-6.

33. Noguchi JL, Liss MA, Parsons JK. Obesity, Physical Activity and Bladder Cancer. Curr Urol Rep 2015;16:74.

34. Tai YS, Chen CH, Huang CY, et al. Diabetes mellitus with poor glycemic control increases bladder cancer recurrence risk in patients with upper urinary tract urothelial carcinoma. Diabetes Metab Res Rev 2015;31:307-14.

35. Oh JJ, Kang MY, Jo JK, et al. Association between diabetes mellitus and oncological outcomes in bladder cancer patients undergoing radical cystectomy. Int J Urol 2015;22:1112-7.

36. Lewis JD, Habel L, Quesenberry C, et al. Proteinuria testing among patients with diabetes mellitus is associated with bladder cancer diagnosis: potential for unmeasured confounding in studies of pioglitazone and bladder cancer. Pharmacoepidemiol Drug Saf 2014;23:636-45.

37. Jahnson S, Hosseini Aliabad A, Holmang S, et al. Swedish National Registry of Urinary Bladder Cancer: No difference in relative survival over time despite more aggressive treatment. Scand J Urol 2016;50:14-20. 
38. Jahnson S, Damm O, Hellsten S, et al. A population-based study of patterns of care for muscle-invasive bladder cancer in Sweden. Scand J Urol Nephrol 2009;43:271-6.

39. Abdollah F, Gandaglia G, Thuret R, et al. Incidence, survival and mortality rates of stage-specific bladder cancer in United States: a trend analysis. Cancer Epidemiol
2013;37:219-25.

40. Engholm G, Hakulinen T, Gislum M, et al. Trends in the survival of patients diagnosed with kidney or urinary bladder cancer in the Nordic countries 19642003 followed up to the end of 2006. Acta Oncol 2010;49:655-64.
Cite this article as: Zang Y, Li X, Cheng Y, Qi F, Yang N. An overview of patients with urothelial bladder cancer over the past two decades: a Surveillance, Epidemiology, and End Results (SEER) study. Ann Transl Med 2020;8(23):1587. doi: 10.21037/ atm-20-2108 


\section{Supplementary}

Table S1 Additional information on urothelial bladder cancer patients included in the study

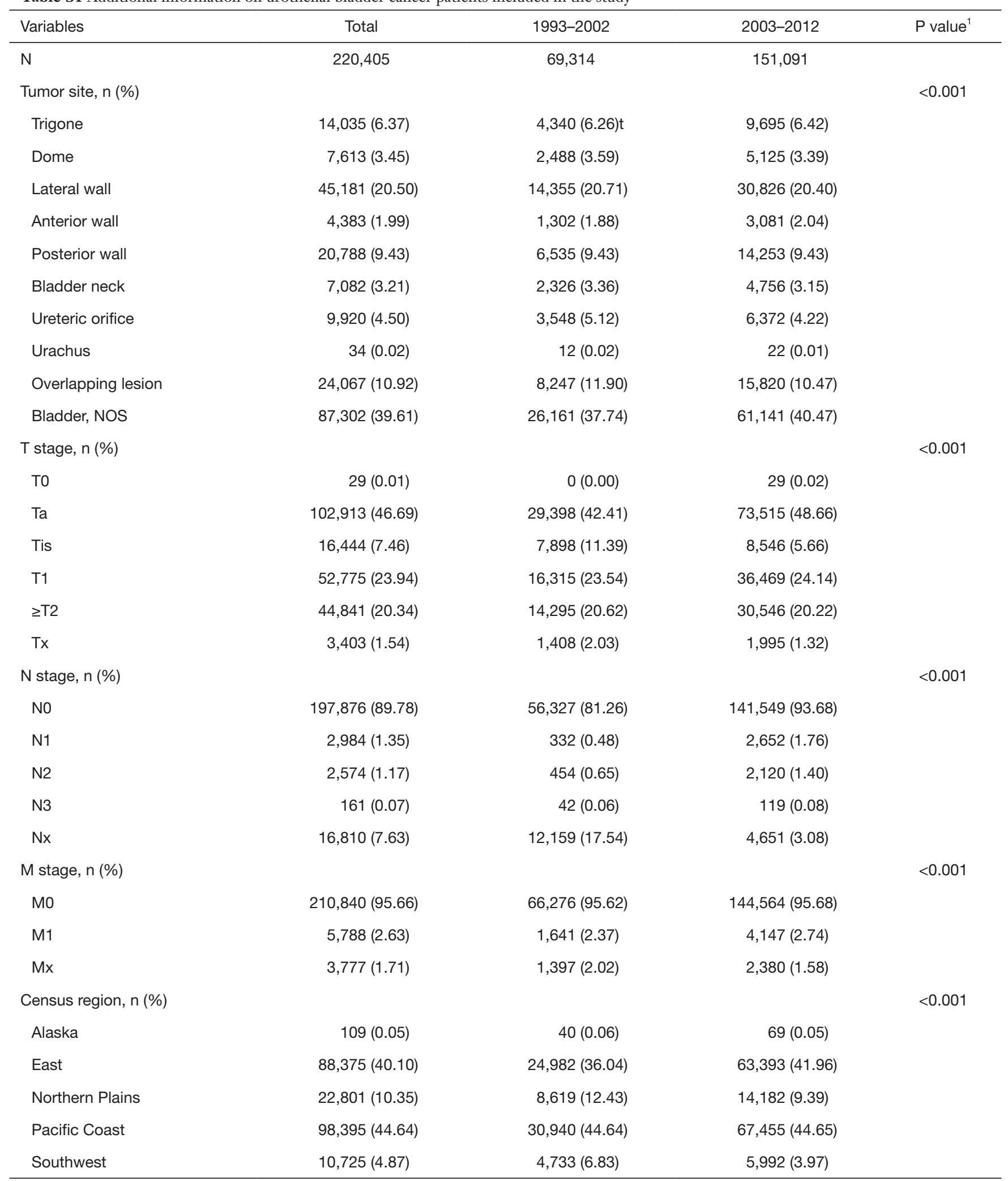

1, comparison between 1993-2002 and 2003-2012. UBC, urothelial bladder cancer; NOS, not otherwise specified. 
A surival curve of Year to diagnosis (Age<60 years old) ( $\mathrm{P}=8 \mathrm{e}-04)$

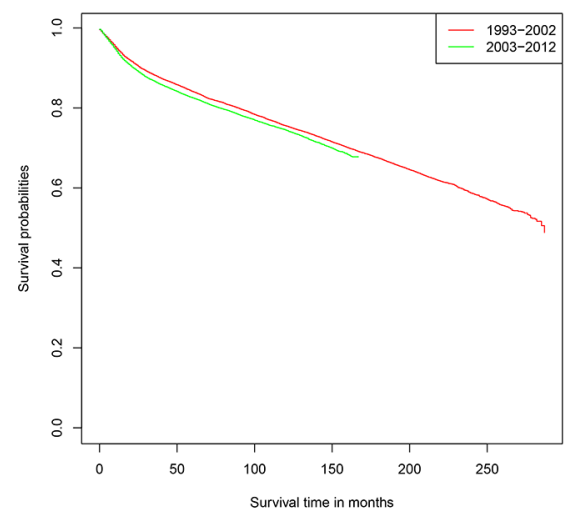

D

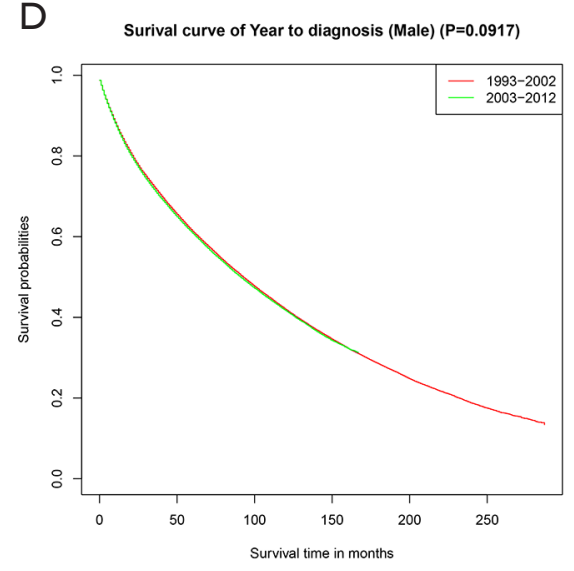

B

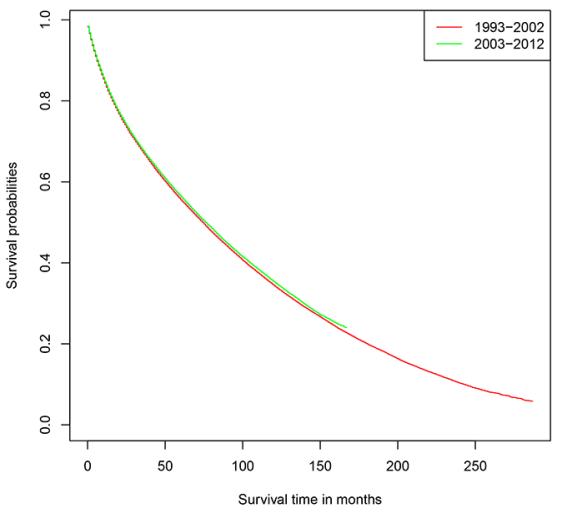

E

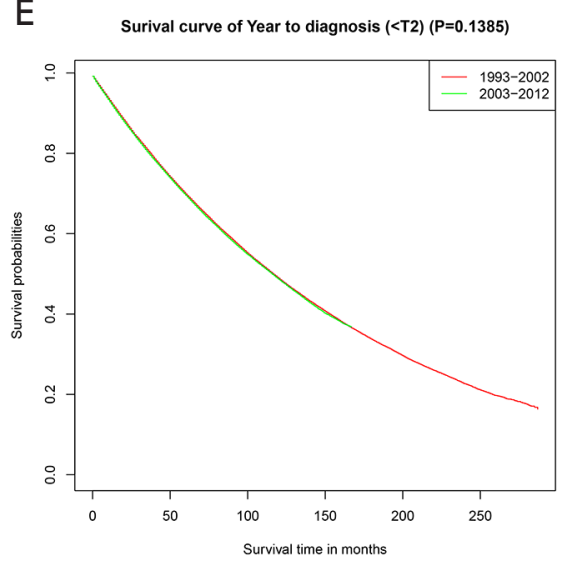

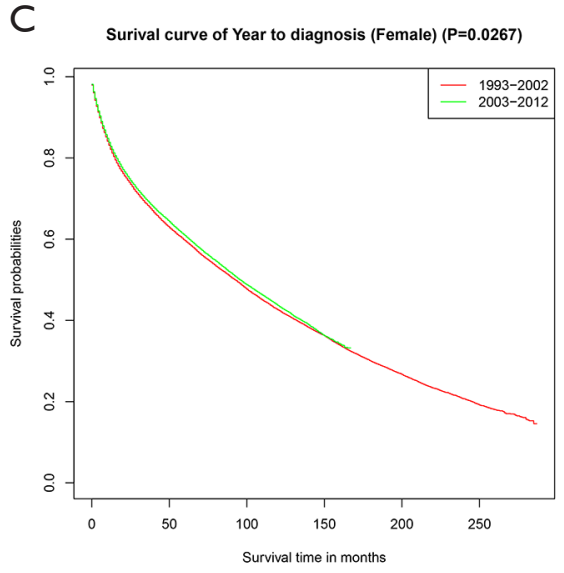

$\mathrm{F}$

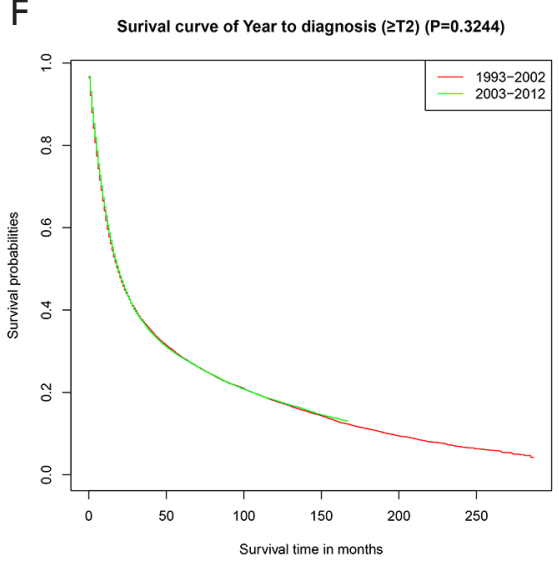

Figure S1 Kaplan-Meier curves of overall survival for urothelial bladder cancer patients in different time periods, stratified by age (A,B), gender $(\mathrm{C}, \mathrm{D})$ and $\mathrm{T}$ stage $(\mathrm{E}, \mathrm{F})$. 
A Surival curve of Year to diagnosis (Age<60 years old) ( $\mathrm{P=8 \textrm {e } - 0 4 )}$

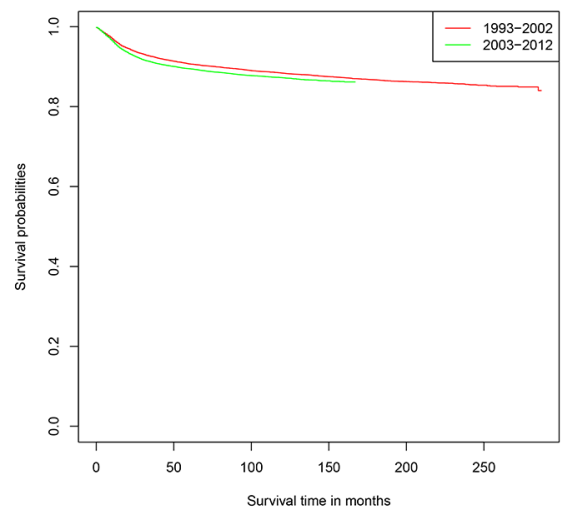

D

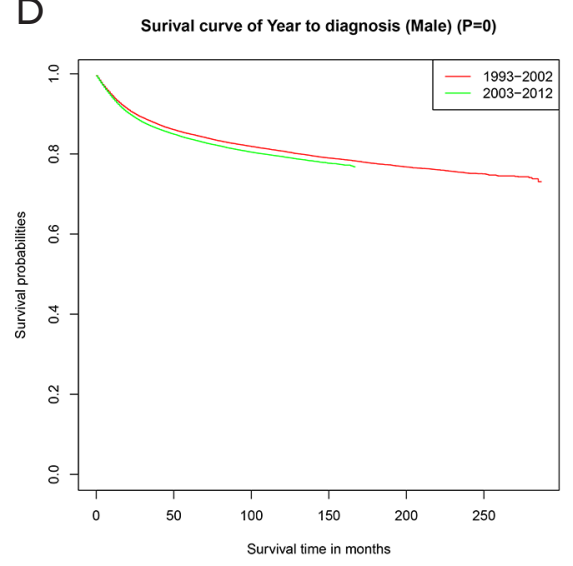

B

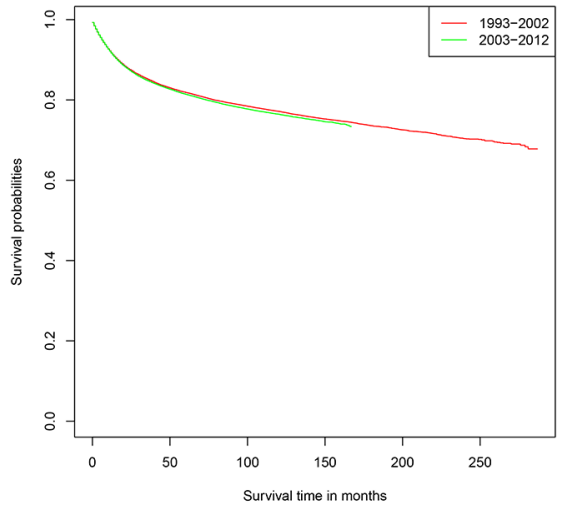

E

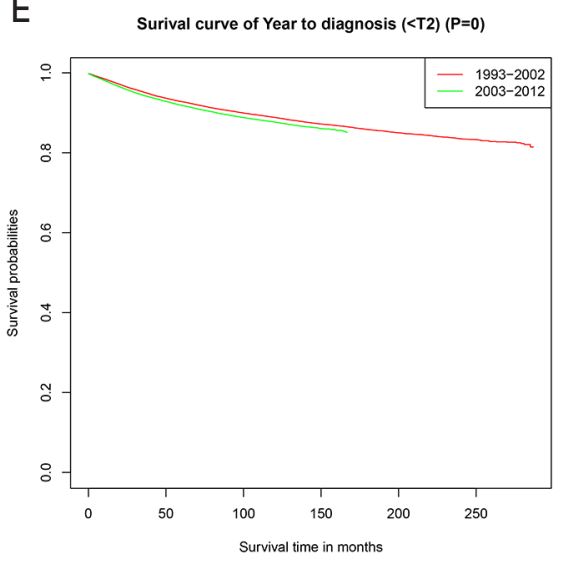

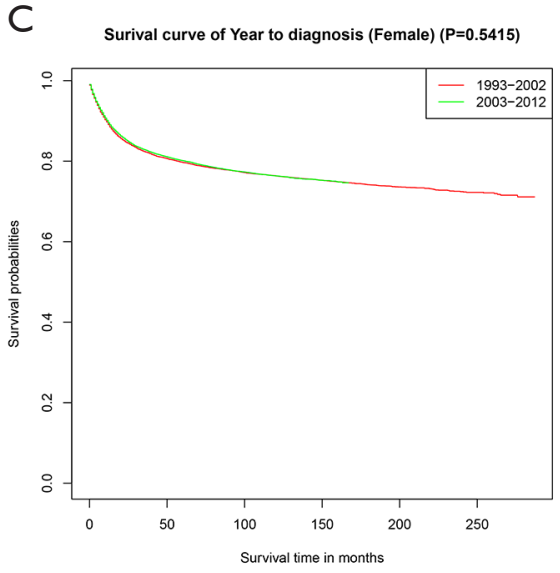

$\mathrm{F}$

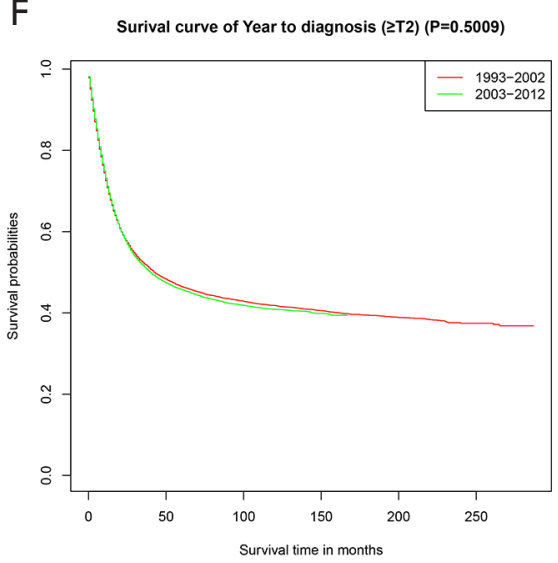

Figure S2 Kaplan-Meier curves of cancer-specific survival for urothelial bladder cancer patients in different time periods, stratified by age $(\mathrm{A}, \mathrm{B})$, gender $(\mathrm{C}, \mathrm{D})$ and $\mathrm{T}$ stage $(\mathrm{E}, \mathrm{F})$. 